\title{
A new form of hereditary short limbed dwarfism with microcephalus
}

\author{
Richard C. Juberg and Madge B. Van Ness \\ Birth Defects Center, Department of Pediatrics, Louisiana State \\ University School of Medicine in Shreveport, Shreveport, Louisiana, and \\ Departments of Human Genetics and Pediatrics, University of Michigan \\ Medical School, Ann Arbor, Michigan, U.S. A.
}

\begin{abstract}
Siblings, one female and one male, were each born approximately 1 month prematurely and showed microcephalus, shortness, and short limbs plus a receding forehead and one peculiarly positioned small toe. Each failed to thrive, and neither made any developmental progress beyond the newborn status. Each exhibited a similar leukemoid reaction, and one died of respiratory infection at 3 months, the other of seizures and central nervous system infection at 5 months.

At autopsy, each had a small brain, hydrocephalus, and bony anomaly of the cranium, the one of the posterior fossa and the other of the foramen magnum; in addition, one had absence of the corpus callosum. The long bones were considered atypical of chondrodystrophy.

The combination of mildly shortened bones of the extremities, moderately anomalous ribs, and slightly flattened vertebrae with microcrania does not resemble any of the previously recognized forms of short limbed dwarfism.

We propose determination by a single, rare, autosomal recessive gene. The parents had greatly different ancestry and their apparent heterozygosity for such a gene made their mating particularly unusual.
\end{abstract}

Received 4 June, accepted for publication 12 September 1974

A number of forms of short limbed dwarfism are diagnosable at birth. Some of the syndromes include other manifestations of abnormality. None recognized to date is associated with microcephalus due to primary anomaly of the brain.

The purposes of our report are: to describe a sibship in which there were two infants similarly affected with short limbed dwarfism, microcephalus, and an anomalous brain, to distinguish them from previously recognized entities, and to propose genetic determination by a single, rare, autosomal recessive gene.

\section{Case Reports}

The proposita (Fig. 1) was the result of the seventh pregnancy of her parents, four of the preceding six conceptions having terminated in spontaneous abortion. She was born 5 weeks before the expected date after a normal gestation for the mother. The presentation was breech. Her weight was $2640 \mathrm{~g}$, length $42 \mathrm{~cm}$, and head circumference $29.5 \mathrm{~cm}$. The head appeared disproportionately small, and the extremities looked unusually short but not as much as in achondroplasia. The infant seemed to be 




Fig. 1. Pedigree of the T. kindred.

normally active except that the upper extremities moved less than the lower. They tended to lay flaccidly at the sides giving the superficial appearance of brachial palsy, although the infant was able to flex and extend them. She showed marked lag of her head, but she could raise it from the prone position and turn it feebly sideways. Her sucking ability seemed normal but the rooting reaction was less than usual. During her first $5 \mathrm{~d}$ she developed jaundice with the total bilirubin rising to $14.6 \mathrm{~g} / 100 \mathrm{ml}$; the mother was $\mathrm{O} R \mathrm{~h}+$ and the infant was $\mathrm{B}$ $\mathrm{Rh}+$ with the most probable genotype of $\mathbf{R}_{1} \mathbf{R}_{2}$. The dye test for toxoplasmosis was negative.

By 2 weeks of age her weight was 3050 $\mathrm{g}$, length $43.5 \mathrm{~cm}$, and head circumference $30.5 \mathrm{~cm}$. At 4 weeks her weight was 3075 $\mathrm{g}$, length unchanged, and head circumference $31 \mathrm{~cm}$. At 2 months her weight was $3650 \mathrm{~g}$, length still $43.5 \mathrm{~cm}$, and head circumference $32 \mathrm{~cm}$. Thus, she continued to be considerably below the third centile for a Caucasian female.

She required hospitalization for $5 \mathrm{~d}$ at the age of $2 \frac{1}{2}$ months with the diagnosis of bronchiolitis, at which time the hematological findings were peculiar. Her hemoglobin concentration initially was $9.5 \mathrm{~g} /$ $100 \mathrm{ml}$, but it increased to $13.5 \mathrm{~g} / 100 \mathrm{ml}$ $3 \mathrm{~d}$ later. Values of white blood counts ranged from 49300 cells $/ \mathrm{m}^{3}$ with $49 \%$ segmented neutrophils, $8 \%$ banded neutrophils, $1 \%$ metamyelocytes, $8 \%$ monocytes, $33 \%$ lymphocytes, and $1 \%$ eosinophils to $14000 \mathrm{cells} / \mathrm{ml}^{3}$ with $20 \%$ segmented and $1 \%$ banded neutrophils, $12 \%$ monocytes, $66 \%$ 
lymphocytes, and $1 \%$ eosinophils. The proportion of reticulocytes ranged from $13.3 \%$ to $8.8 \%$. The platelets appeared to be normal, and one count showed 373000/ $\mathrm{ml}^{3}$. Her bone marrow appeared slightly hypocellular but the myeloid:erythroid ratio was normal at 1.4:1. The hematologist concluded that the number of leukocytes might be an unusual response to the severe infection, albeit presumably viral in origin.

The infant expired shortly after a second hospitalization for another respiratory disease at the age of 3 months. At the time of the autopsy her weight was $4010 \mathrm{~g}$, length $44 \mathrm{~cm}$, and head circumference $31 \mathrm{~cm}$. There was evidence of acute purulent pharyngitis, laryngitis, tracheitis, bronchitis, and interstitial pneumonitis. The forehead receded posteriorly. The brain weighed 195 g (expected weight was $403 \mathrm{~g}$ (Potter \& Adair 1949)). There was diffuse absence of cerebral tissue with hydrocephalus, widely dilated ventricles, and agenesis of the corpus callosum. The posterior cerebral fossae were abnormally developed, showing marked shallowness and lacking the usual concavity of the inner surface. This was flattened and corresponded to that of the posterior inferior surface of both cerebellar hemispheres. In contrast, the anterior and middle cerebral fossae appeared to be normally developed. Other bones were also significantly abnormal. There was definite flaring of the costochondral junctions bilaterally. The head and the neck of the right humerus were examined and there appeared to be widening of bone at the epiphyseal plate. Following decalcification of the bones the cartilaginous columns at the epiphyseal plates appeared to be shorter than normal.

The roentgenograms shown in Figs. 2, 3, and 4 were made shortly after birth. The skull (Fig. 2) showed microcrania, craniofacial disproportion, open fontanels, and no cvidence of stenosis. The ribs (Fig. 3) appeared somewhat short and straight but not



Fig. 2. Skull of proposita at $4 \mathrm{~d}$ of age showing microcrania and craniofacial disproportion. 


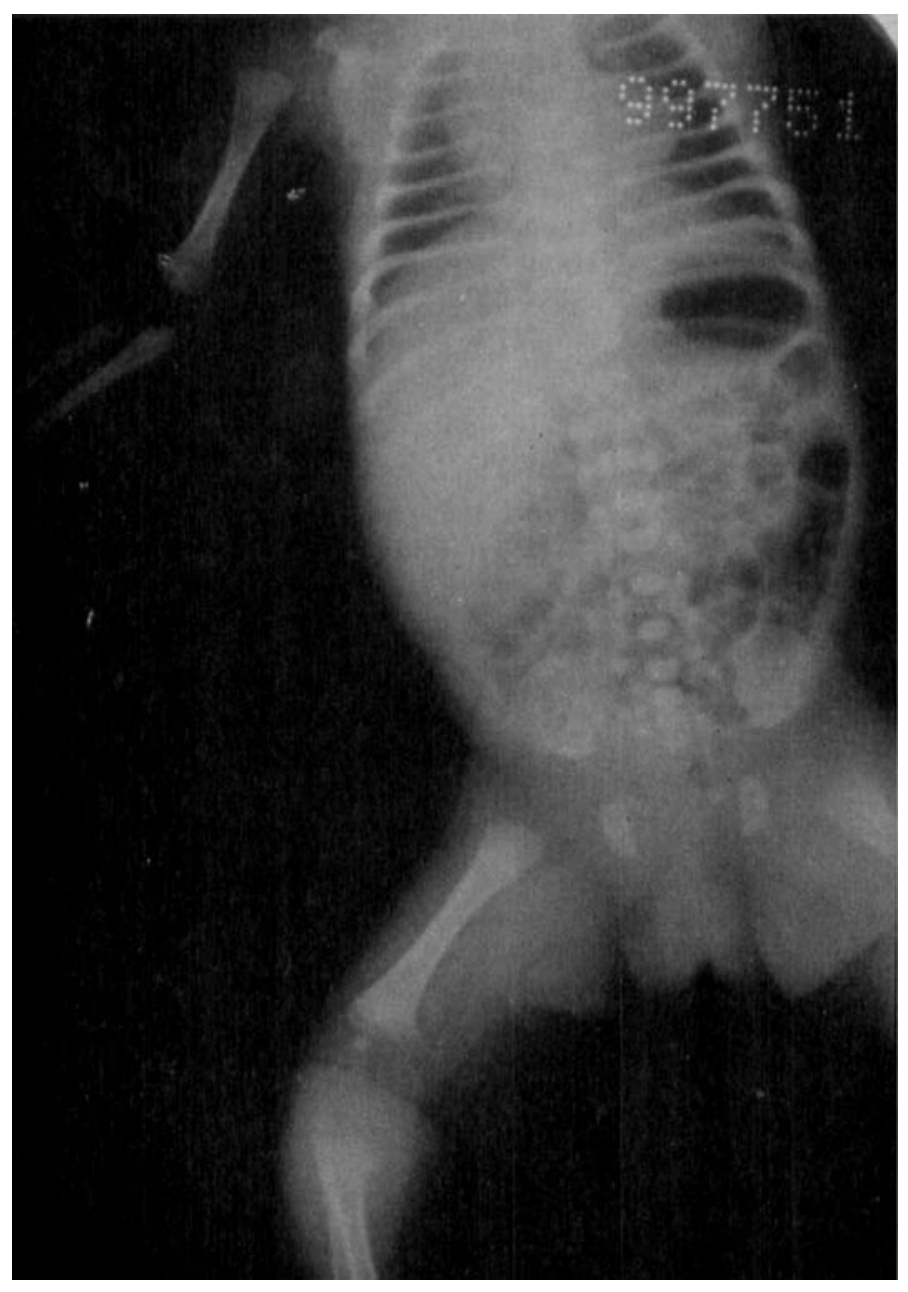

Fig. 3. Trunk of proposita at 3 d of age showing shortened ribs and flattened vertebrae.

stubby or thick. Their anterior ends were abnormal due to cupping and widening. There appeared to be some flattening of the vertebrae although those in the lumbar region did not show well in the lateral view. The appearance of the pelvis and hips was interpreted by different observers as either normal or showing some stubbiness of the iliac bones. The bones of the extremities (Fig. 4) were shortened but not otherwise abnormal.

At the time of the birth of the proposita, the parents were struck by her considerable resemblance to their first live born offspring, a male, who expired at 5 months of age. This had been in their previous residence outside of the United States. At the time of birth of the male infant the mother was 26 and the father 24 years old. There was evidence of threatened abortion in the first trimester, and the birth occurred about 4 weeks before the anticipated date. His weight was $3000 \mathrm{~g}$, length $45.7 \mathrm{~cm}$, and head circumference $31.8 \mathrm{~cm}$. His general condition was only fair due to sternal retraction, grunting respirations, and abnormal 
muscle tone. He showed considerable edema, specifically of the head, face, neck, and extremities. The examining physician noted in his record that the right smallest toe was abnormal in position - attached lower than normal and bent forward - a feature also present in the proposita which was called to our attention by the parents. The edema cleared, and he was discharged from the nursery after $6 \mathrm{~d}$.

At 2 weeks of age his weight had decreased to $2570 \mathrm{~g}$. He continued poorly and was readmitted to the hospital at the age of 5 weeks because of regurgitation and failure to grow. His head was $31.1 \mathrm{~cm}$ in circumference, and it was almost oxycephalic. The examiner noted a high arched palate and a right inguinal hernia, but the extremities appeared to be normal. No measurements were made of the limbs of this or the preceding infant.

At this time, studies of the blood showed: hemoglobin $11 \mathrm{~g} / 100 \mathrm{ml}$, white blood cell count $62000 / \mathrm{ml}^{3}$ with $2 \%$ blast forms, $27 \%$
Fig. 4. Trunk and one lower and one upper extremity of proposita at $3 d$ of age showing short limbs.






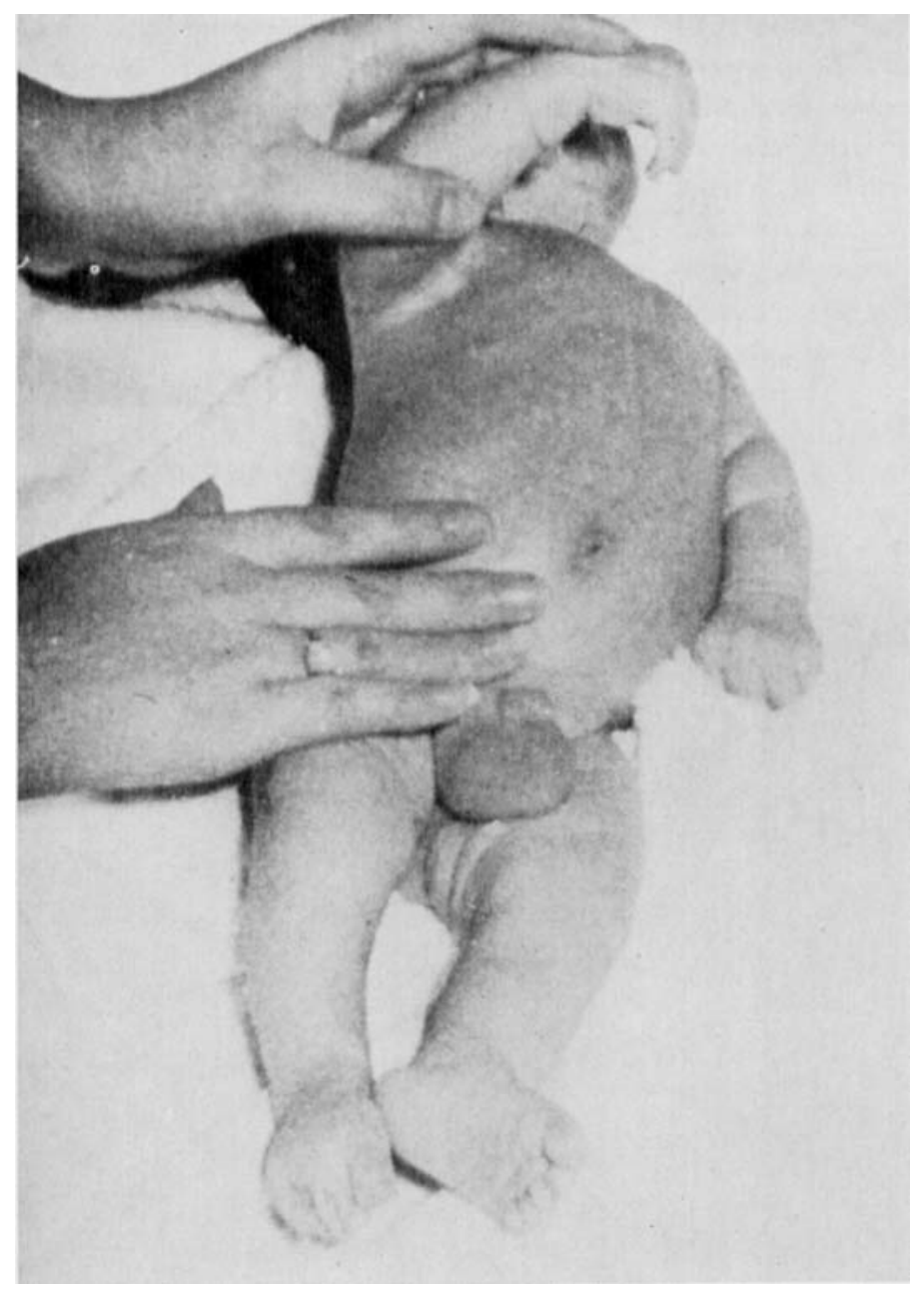

Fig. 5. Male sibling at 2 months.

myelocytes, $9 \%$ juveniles, $16 \%$ banded and $34 \%$ segmented neutrophils, $12 \%$ lymphocytes, and an adequate number of platelets. Examinations of bone marrow were successively suggestive of acute granulocytic leukemia, granulocytic hyperplasia or nonlipid reticuloendotheliosis, erythroid hyperplasia and macrocytic anemia, and finally, leukemoid reaction. In the 3 weeks after admission, the white blood cell count diminished to $13250 / \mathrm{ml}^{3}$ with $46 \%$ neutrophils and $54 \%$ lymphocytes; when the he- moglobin dropped to $7.9 \mathrm{~g} / 100 \mathrm{ml}$, he received two blood transfusions. The result of an electroencephalogram was interpreted to be definitely abnormal.

Roentgenograms of this infant were not available to us, but the reports indicated the following. There were no intracranial calcifications. There were no abnormalities in the bony thorax, the mediastinal or cardiac contours, or in the lungs. There was normal mineralization of all bones, and skeletal maturation was appropriate for the 
age. At 5 weeks of age irregular, stippled mineralization of the ossification centers of the tarsal bones and of the femoral capital epiphyses was reported, and peculiar, small spotted calcifications were apparent in the soft tissues about the knees. Three weeks later, films of the chest and abdomen, which included the proximal bones of the extremities, showed no abnormalities.

The infant did not suck adequately so that tube feeding was necessary. During its 3 months in the hospital, it gradually gained to about $4100 \mathrm{~g}$. However, it began to have generalized seizures which eventually became severe enough to require oxygen therapy for cyanosis, and the infant expired during a period of continuous seizures.

Post mortem examination showed a small cranium with a small brain which weighed just $200 \mathrm{~g}$. The lateral ventricles were markedly dilated, and both internal and external hydrocephalus were evident. There was marked deformity at the base of the skull where the foramen magnum measured only $0.9 \mathrm{~cm}$ in diameter. The bones were thought to show "atypical chondrodystrophy."

Four of the five other pregnancies of this couple had resulted in spontaneous abortion; three occurred within the first 3 months of pregnancy, and one female was lost in the fifth month. There was one normal male child.

Ancestry of the couple was considerably different, because she was a Japanese from Japan, and he was a Pole from Michigan. Neither knew of similarly affected infants in their families.

\section{Discussion}

Characteristics of the disorder

Their births and then the inadequate growth and development of the two infants were considerably alike. Both were born before term and were small in weight, height, and head circumference. Their subsequent growth was quite inadequate, and neither showed neurological development beyond that of the newborn.

Both were morphologically bizarre with a small cranium, receding forehead, and shortened limbs. Each had a similarly small brain with hydrocephalus and bony abnormality, the one of the posterior fossae and the other of the base of the cranium. In addition, both had a peculiarly attached right smallest toe.

Functionally, both failed to cope normally with respiratory infection, developed the same leukemoid reaction, and died within 6 months.

Therefore, because of these similarities we considered it reasonable to conclude that they had the same disorder.

\section{Differentiation from the recognized forms of short limbed dwarfism}

In the differential diagnosis of short limbed dwarfism which is diagnosable at birth, Kaufman et al. (1970) listed 11 disorders. We believe that it is necessary to use only clinical manifestations in order to distinguish the anomalies in the two siblings we report from previously recognized entities. This is to say that we consider a genetic argument insufficient, a pathological argument impossible, and an argument based on survival unsound. Thus, we believe that distinction according to the apparent manner of monogenic transmission would be insufficient because of the possibility of genetic heterogeneity. We cannot prove the uniqueness of our cases pathologically, because we did not have adequate microscopic studies of the tissues. Finally, we think that lethality is an unsatisfactory criterion.

Because of its frequency as a cause of short limbed dwarfism, achondroplasia was an early consideration, and, indeed, atypical achondroplasia was suggested by different 
radiologists and pathologists who examined the two infants. But the structure of the bones in the extremities is clearly distinctively different in achondroplasia than in these two infants, the cranium and pelvis are likewise characteristically different, and the functional responses in achondroplasia are not abnormal. Thanatophoric dwarfism has lately been described and discriminated from achondroplasia, but the alteration in bone structure in this disorder is general and considerable and readily distinguishable from the rather mild effects we observed. Another disorder, achondrogenesis, results in poor mineralization, so that sometimes the bones are not even visualized. Because the density of the bones in our two cases seemed to be normal, we eliminated this entity. Early death occurs in both thanatophoric dwarfism and achondrogenesis, but it is generally earlier than in the two siblings we have described. In addition, our cases did not resemble the two siblings reported in 1972 by Harris et al. who had some features of both thanatophoric dwarfism and achondrogenesis.

The configuration of the chests in the two siblings was not like the abnormally small thoracic cage seen in asphyxiating thoracic dystrophy, in which constriction in both dimensions is characteristic; nor did our cases show the flared ilia evident in this entity. Further, our cases did not have either flaring of the lower ribs or polydactyly. We next dismissed the possibility of chondroectodermal dysplasia because of lack of any of the following found in this disorder: polydactyly, small thorax, congenital heart defects, and underdeveloped nails. The absence of fine, sparse, light hair, small cystic cartilaginous areas in the epiphyses, and flaring of the metaphyses seemed to rule against consideration of metaphyseal chondrodysplasia (also known as cartilage hair hypoplasia).

Our cases did not have the clinical mani- festations of diastrophic dwarfism, namely, clubfeet, abnormal thumbs, and deformity of the external ears, nor apparently the roentgen signs, though we were deprived of good views of metacarpals and metatarsals. Similarly, we did not see either clinical or roentgen signs of metatrophic dwarfism, that is, joint enlargement, marked metaphyseal flaring, vertebral body flattening, and epiphyseal irregularity and fragmentation.

The features of osteogenesis imperfecta, including fractures, deformities, cranial largeness with facial smallness, blue sclerae, and flattened vertebrae, were not present in our infants. Because of the lack of a short trunk and characteristic vertebral abnormalities, we put aside the possibility of spondyloepiphyseal dysplasia congenita.

Finally, the possibility of chondrodysplasia punctata remains to be considered from the list of Kaufman et al. (1970). Some stippling was reported on one occasion in the male infant and apparently not seen subsequently, at least it was not mentioned; the calcification seen was not in the area of the carpal and the tarsal bones. We saw nothing of this sort in the second infant. Other than short limbs, our infants did not manifest the kind of clinical anomalies congenital heart defects and cataracts - frequently encountered with the cartilaginous abnormality. Nor did they show the roentgen characteristic, coronal cleft vertebrae. We rejected this syndrome.

We have compared the findings of the bones of the trunk and extremities in our infants with the pathological features in the preceding 11 forms of short limbed dwarfism and also noted other abnormalities of those syndromes not seen in our infants. We have done so without mention of the microcephalus and anomalies of the brain of our infants. We argued in this manner for we wished to establish the uniqueness of the two siblings based on their short limbs, 
because it is possible that the cranial and central nervous system defects were coincident and independently determined. Primary microcephalus may be genetically determined; though it is genetically heterogenous (Cowie 1960), an autosomal recessive form has been recognized (Kloepfer et al. 1964). Nevertheless, we concluded that the anomalies of the bones and the brain were from the same single cause.

\section{Genetic implications}

Although our investigations were necessarily limited, our inquiries concerning environmental causes were unproductive, not only of a repeated incident but also of a single event in either pregnancy, and we reasoned that the disorder was probably genetically determined. It would most likely be monogenic; further, because of the rarity of recurrent mutation, it would likely be autosomal recessive.

If the disorder is a new form of short limbed dwarfism, then it would seem to be due to a rare gene. Thus, it is curious that the disorder should initially be recognized from the mating of two persons with such different ancestry.

\section{Acknowledgements}

Drs. Walter T. Snow and James R. Marquis contributed to our interpretation of the roentgenograms.

\section{References}

Cowie, V. (1960). The genetics and sub-classification of microcephaly. J. ment. Defic. Res. 4, 42-47.

Harris, R., J. T. Patton \& A. J. Barson (1972). Pseudo-achondrogenesis with fractures. Clin. Genet. 3, 435-441.

Kaufman, R. L., D. L. Rimoin, W. H. McAlister \& J. M. Kissane (1970). Thanatophoric dwarfism. Amer. J. Dis. Child. 120, 53-57.

Kloepfer, H. W., R. V. Platou \& W. Hansche (1964). Manifestations of a recessive gene for microcephaly in a population isolate. $J$. Génét. hum. 13, 52-59.

Potter, E. L. \& F. L. Adair (1949). Fetal and Neonatal Death. 2nd. ed. Chicago, University of Chicago Press. p. 11.

Address:

Richard C. Juberg, M.D., Ph.D.

Louisiana State University School of

Medicine in Shreveport

P. O. Box 3932

Shreveport, Louisiana 71130

U.S. A. 